\title{
ANONIMATO DE VIDA E DE MORTE: FIGURAS CONTEMPORÂNEAS DE UMA TRAMA SOCIAL VIOLENTA
}

\author{
Viviani Sousa Catroli
}

\begin{abstract}
RESUMO. O presente artigo pretende traçar as bordas da especificidade do fenômeno da violência na contemporaneidade. Mais especificamente, procura evidenciar de que forma este novo delineamento, aliado à lógica de controle global, irá imprimir suas marcas na sociedade brasileira. A partir desta articulação entre um funcionamento global e sua incidência no contexto específico do processo histórico brasileiro, iremos pensar sobre os impasses trazidos por esta nova especificidade do fenômeno da violência e os desafios para os processos de subjetivação e inscrição no laço social do contemporâneo. Interessar-nos-á conduzir esta discussão a partir da hipótese de que haveria uma desfiguração do outro social, possível graças a uma zona de anomia, onde a legalidade e a ilegalidade se confundiriam. Desta forma, a partir da intersecção entre os modos de subjetivação do contemporâneo e as práticas do exercício do poder, discutiremos os impasses à singularização num contexto desértico da mais completa dessubjetivação do socius.
\end{abstract}

Palavras-chave: Violência, anomia, subjetividade.

\section{ANONYMITY OF LIVE AND DEATH: CONTEMPORARY IMAGES OF A VIOLENT SOCIABILITY}

\begin{abstract}
The proposal of this paper is to consider some questions regarding the new boundaries of the phenomenon of contemporary violence. More specifically, how this context, allied to the logic of global control, imprints its marks on Brazilian society. From this conjunction between a global functioning and its effects on the Brazilian historical process, we will pass on to the bottlenecks and the challenges for the subjective process and for the inscription into the social tie on the contemporary. It is this context, we will shall pursue the discussion with the hypothesis that there occurs a disfiguration of the social other, possibly stemming from a zone of anomia, where legality and illegality are interwoven and at times confused. In this way, from the intersection of the subjectivization forms of the contemporary and the practices of the exercise of power, we will discuss the impediments to singularization in a context entirely barren at the limits of the extreme de-subjectivation of the socius.
\end{abstract}

Key-words: Violence, anomia, subjectivity.

Key words: Violence, anomia, subjectivity.

\section{EL ANONIMATO DE LA VIDA Y DE LA MUERTE: FIGURAS CONTEMPORÁNEAS DE UNA TRAMA SOCIAL VIOLENTA}

RESUMEN. El presente artículo pretende trazar las bordas de la especificidad del fenómeno de la violencia en la contemporaneidad. Aún, más específicamente, se trata de evidenciar de qué forma esta nueva delineación, aliada a la lógica de control global, va a imprimir sus marcas en la sociedad brasileña. A partir de esta articulación entre un funcionamiento global y su incidencia en el contexto específico del proceso histórico brasileño, vamos a pensar sobre los dilemas traídos por esta nueva especificidad del fenómeno de la violencia y los desafíos para los procesos de subjetivación e inscripción en el lazo social de la contemporaneidad. Nos interesará conducir esta discusión a partir de la hipótesis de que habría una desfiguración del otro social, posible gracias a una zona de anomia, donde la legalidad y la ilegalidad se confundirían. De esta forma, de la intersección entre los modos de subjetivación de lo contemporáneo y las prácticas del ejercicio del poder, discutiremos los dilemas a la singularización en un contexto desértico de la más completa desubjetivación de lo socius..

Palabras-clave: Violencia, anomia, subjetividad.

O mundo contemporâneo se aterroriza diante das múltiplas formas do exercício da violência que se apresentam no horizonte de cada território. O fenômeno da violência se irradia em aliança com a

* Doutoranda em Psicologia Social, Pontifícia Universidade Católica de São Paulo-PUC/SP, Brasil. Doutoranda (co-tutela) Sciences de l'éducation, Université Paris 8, França. 
especificidade dos conflitos histórico-políticos locais de cada território, mas também será fiel aos contornos globais do sistema capitalista contemporâneo. Há muito sabemos que tais mudanças podem vir a produzir alguns efeitos subjetivos devastadores, como as patologias narcísicas e a impossibilidade da experiência do luto no caso das perdas por morte violenta. Enfim, a violência como fenômeno será produtora de um imaginário social que irá imprimir suas marcas no corpo dos sujeitos do contemporâneo.

Assim, primeiramente, iremos traçar as novas bordas que a violência, enquanto fenômeno social, irá assumir a partir da emergência das sociedades de controle global já no início do século XX. Ainda, mais especificamente, iremos evidenciar de que forma esta nova lógica de controle global irá imprimir suas marcas na sociedade brasileira e irá compor, conjuntamente com o singular processo de formação de nossa sociedade, um novo quadro do fenômeno da violência em nossos dias. Será a partir desta que iremos evidenciar alguns dos efeitos desta nova especificidade do fenômeno da violência para os processos de subjetivação e inscrição no laço social no contemporâneo.

\section{DA DISCIPLINA AO CONTROLE: A DESFIGURAÇÃO DO OUTRO SOCIAL}

Tais questões podem ser evocadas a partir da constatação feita por Foucault (1984), no primeiro volume de sua História da Sexualidade I. A Vontade de Saber, de que nunca, antes do século XIX, as guerras haviam sido tão sangrentas. $\mathrm{O}$ advento do capitalismo industrial produziu suas marcas não apenas na reorganização dos modos de produção, mas também nos processos de subjetivação da modernidade. Essa reorganização específica dos modos de produção e seus efeitos para a construção dos corpos individuais e para as instâncias grupais de organização marcaram a formação de um novo modo de exercício do poder, chamado por Foucault (1987) de as sociedades disciplinares.

A formação das sociedades disciplinares pode ser circunscrita a partir do final do século XVII e início do século XVIII, tendo o seu apogeu no século XIX. Sua constituição ganhou visibilidade, primeiramente, pela reorganização do sistema judiciário e penal. A partir desse século os mecanismos de poder não iriam mais atuar por meio dos rituais individuais de punição, mas sim, a partir de técnicas de vigilância e controle contínuos sobre todo o corpo social. Esse exercício do poder não estará mais nas mãos da vontade do soberano, mas sim, será regido por leis necessárias, aplicáveis indistintamente a todos. Assim, podemos deduzir que o antigo malfeitor que, com seu ato, infligia uma ofensa ao soberano, irá se transformar num criminoso que se insurge contra o corpo da sociedade (Foucault, 2001).

Alguns outros aspectos importantes serão desenvolvidos por Foucault (1987) no sentido de nos fornecer os contornos precisos de uma sociedade que, cada vez mais, irá erigir-se a partir da complexificação das técnicas de um poder fundado nos moldes da vigilância e do controle. Assim, as tecnologias de poder da modernidade iriam fazer dobra e se afirmar num duplo funcionamento. $\mathrm{O}$ primeiro deles, ainda no século XVII, foi nomeado anatomopolítica dos corpos individuais, e se instaurou como as disciplinas. As disciplinas foram todos os métodos que tornaram possível o controle detalhado de todas as operações do corpo, sujeitando suas forças e impondo a elas uma relação de utilidade-docilidade. De acordo com essa lógica, o corpo se torna o objeto e o alvo do poder.

Em concordância com este funcionamento, observa-se durante a segunda metade do século XVIII que uma diferente tecnologia de poder começa a ser traçada. Trata-se de uma biopolítica da espécie humana. Essa nova tecnologia do exercício do poder não exclui a estratégia disciplinar, mas, ao contrário, soma-se a ela, complementa-a e a integra. A marca desta nova estratégia de exercício do poder é o aparecimento de um novo fenômeno, um novo personagem, a saber, a população. A biopolítica das espécies vai se debruçar sobre os problemas referentes à população. De acordo com essa lógica, importará menos tratar do corpo individual do que dos fenômenos de conjunto, como forma de se obterem estados globais de equilíbrio e regularidade (Foucault, 1999). A partir da junção dessas duas estratégias do exercício do poder, uma anatomopolítica dos corpos tecnologia disciplinar do corpo - e de uma biopolítica das espécies - tecnologia regulamentadora da vida - é que se deu a saída para um controle completo de todas as instâncias do corpo social.

Sendo assim, o sistema punitivo das sociedades disciplinares que se estabelecia segundo essa nova lógica de gerir a vida se tornaria incompatível com a lógica anterior, da soberania, de causar a morte através de rituais de punição tão requintados. A punição vai se tornar a estratégia última, utilizada apenas quando , por alguma razão, falha o controle dos corpos e da vida. Desta forma, chegamos a um estranho paradoxo apontado por Foucault (1984), a saber: como um poder que tem como função assegurar a vida de suas populações, prolongar sua duração, multiplicar suas possibilidades, desviar seus acidentes e compensar 
suas deficiências, pode matar, expor à morte não só seus inimigos, mas até seus próprios cidadãos?

Como saída para o problema, Foucault nos apresenta o racismo como a condição para que se possa exercer no biopoder o direito de matar. $\mathrm{O}$ racismo será, então, o fundamento inserido no biopoder para demarcar aqueles que poderão viver e aqueles que deverão morrer, de acordo com critérios biológicos que irão defasar, no interior de uma população, de uma raça, uns grupos em relação a outros. Essa teoria dará suporte, também, ao direito de eliminar o maior número de indivíduos de espécies ditas inferiores, pois somente dessa forma se garantiria a sobrevivência das raças superiores. De acordo com Foucault (1999 p.306), "tirar a vida, o imperativo da morte, só é admissível, no sistema do biopoder, se tende não à vitória sobre os adversários políticos, mas à eliminação do perigo biológico e ao fortalecimento, diretamente ligado a essa eliminação, da própria espécie ou da raça".

Pergunta-se, não obstante: em que essa discussão irá nos ajudar a pensar as questões das práticas de extermínio postas em prática na contemporaneidade? Vivemos, ainda, imersos nessa mesma lógica moderna de exercício do poder? De acordo com Deleuze (1992), em seu pequeno artigo Post-scriptum sobre as sociedades de controle, a ordem disciplinar moderna é o que gradativamente deixamos de ser. A contemporaneidade é regida pela lógica do controle. Essa será a afirmação sustentada por ele, a partir do traçado de uma série de contrapontos entre as sociedades disciplinares e a nova lógica do controle global.

Grosso modo, enquanto as estratégias do poder disciplinar atuavam sobre os corpos, ao mesmo tempo individuando-os, controlando suas forças individuais e inserindo-as no sistema de produção capitalista, massificava-as e as transformava em fenômenos de conjunto, ou seja, transformava os corpos individuais em número estatísticos e em dados matemáticos. Desta forma, na mecânica do poder disciplinar, o poder se exercia com o controle sobre cada um e sobre todos, ao mesmo tempo; já nas sociedades de controle, em contrapartida, irá importar menos a assinatura, o nome próprio de cada um, ou o número de série que irá identificá-lo num fenômeno de conjunto. No controle, o que irá importar é quem detém a senha. A senha é o que vai garantir o acesso à informação, essencial no mundo contemporâneo informatizado; uma senha que por um lado nos descaracteriza, mas por outro permite que sejamos rastreados, monitorados, controlados e identificados em tempo integral dentro de um espaço global.
Desta forma, o que temos como especificidade na transposição do exercício do poder das sociedades disciplinares para as sociedades de controle é a efetivação de um processo de sobreposição do mecanismo biopolítico sobre o mecanismo anatomopolítico. Essa sobreposição seria como uma sofisticação do modelo de vigilância disciplinar exercido por uma dupla engrenagem complementar, a qual, na contemporaneidade, afirmaria sua eficiência e sua intensidade mediante prevalência da engrenagem biopolítica. Seria como se na contemporaneidade os mecanismos de controle das populações - ou seja, o pilar biopolítico -, ganhassem uma suficiente autonomia, e agora, por si sós, conseguissem realizar um duplo objetivo, qual seja, vigiar e controlar os corpos e as massas populacionais por meio de um olhar onipresente (Catroli, 2003), um olhar que precisaria cada vez menos dos muros institucionais disciplinares de vigilância. $\mathrm{O}$ local privilegiado para o exercício de um controle global efetivo é agora o ilimitado território da vida nua ${ }^{1}$.

Não obstante, assim como nas sociedades disciplinares se delimitivam as bordas do pertencimento social, excluindo-se todo o campo do não-conforme, nas sociedades de controle, em contrapartida, serão rechaçados todos aqueles que não detiverem a senha de acesso às benesses do capital globalizado; melhor dizendo, todos aqueles que forem pobres demais para serem incluídos no sistema de endividamento capitalista, mas ainda numerosos demais para o encarceramento (Deleuze, 1992).

Neste ponto, podemos observar um deslocamento na questão do princípio de seleção, na forma como concebido na modernidade e como se configura hoje, na contemporaneidade. Ao contrário do princípio de seleção baseado nas teorias racistas modernas, as quais hierarquizavam uma raça em detrimento de outra, na contemporaneidade tende-se a eliminar, a excluir em guetos e favelas e separar através do bom e velho encarceramento aqueles que forem pobres demais para a dívida capitalista. Destarte, no primeiro momento haveria uma lógica do que excede, do que é externo à organização e que, se não for passível de normatização, sê-lo-á de extermínio; no segundo, uma lógica do que pertence à própria organização e que constitui a própria engrenagem do exercício do poder do capitalismo mundial do controle.

A idéia de vida nua será melhor trabalhada no decorrer do texto, a partir do trabalho de Agamben (2002). Esta noção se refere, precisamente, aos fenômenos naturais concernentes a esfera da vida, como o nascimento, a morte, etc. que, passarão a ser compreendidos dentro de um campo político. Esta incorporação receberá o nome de biopolítica. 
O "inimigo social", que era até então concebido como um perigo biológico, um agente externo à organização, e que deveria ser combatido para não macular a pureza de uma determinada raça, na contemporaneidade se transforma. Ele deixa de ser uma ameaça externa e passa a ser efeito do próprio sistema capitalista. Os efeitos dessa nova maquinaria são devastadores, pois quando a ameaça perde o seu caráter externo e passa a integrar o próprio movimento do capitalismo globalizado, o "inimigo" assume uma face nebulosa. O "inimigo", na contemporaneidade, torna-se indiscernível na corrente de fluxos que movimenta o capital. O "inimigo" não é externo ao movimento, ao contrário, ele o integra. Essa indiscernibilidade faz com que tudo, inclusive o outro semelhante, possa ser experimentado como ameaçador (Catroli, 2003).

Essa nova lógica do inimigo irá contribuir para um novo fenômeno característico das sociedades contemporâneas: o esgarçamento das normas mediadoras da relação entre indivíduos. No momento deste esgarçamento da norma, certa zona de anomia ${ }^{2}$ se estabeleceria como afrouxamento do consenso normativo que regula a relação social. As regras sociais passariam a ser reorganizadas circunstancialmente a cada encontro com o outro, e neste lugar teríamos a emergência do fenômeno da violência em sua modulação contemporânea.

Ora, não podemos desconsiderar a função das leis para as sociedades. Trata-se de um modo de regulação e de limitação do gozo do sujeito para que, nesta perda, nessa impossibilidade de satisfação, possa-se, como compensação, fazer laço social com o outro ${ }^{3}$. Nas palavras de Vilhena e Santos, "Para que seja possível um lugar para o Sujeito é fundamental que a lei tenha valor e para tal é preciso que ela seja justa, a todos se aplique e a todos represente. A lei existe não para humilhar e degradar o desejo, mas para estruturá-

2 O conceito de anomia foi inicialmente trabalhado por Durkheim, em 1897, em seu tratado sobre o suicídio. Neste artigo, retomaremos o uso do conceito feito por Durkheim para situá-lo num contexto diverso, o da contemporaneidade. Desta forma, chegaremos à ideia trazida por Agamben (2002) de que em determinados territórios socias teríamos a experiência de uma zona de anomia.

3 Não nos aprofundaremos, neste artigo, na distinção entre as leis do Direito e a lei simbólica; no entanto, não podemos deixar de mencionar que ambas incidem sobre o gozo do sujeito. As leis do Direito regulariam o impulso a fazer do outro objeto da vontade do sujeito; enquanto a lei simbólica estruturaria o sujeito em sua entrada no campo da linguagem. (Quinet, 2003) lo, integrando-o no circuito do intercâmbio social". (Vilhena \& Santos, 2000)

\section{O CONTROLE, A ANOMIA E A EXCEÇÃO}

Agamben (2002) irá se apropriar do conceito de anomia construído por Durkheim em 1987 em seu tratado sobre o suicídio. Nessa obra podemos nos deter no esforço de Durkheim (1987/1977) para traçar o papel moderador que deveria ser exercido pela sociedade e todas as instituições que a compõem, cuidando assim de fixar os limites além dos quais as paixões não deveriam se manifestar. No entanto, quando a sociedade está perturbada, como nos diz Durkheim, esse controle se desestabiliza - o que, na concepção do autor, irá contribuir para o aumento das taxas de suicídio, dando início a um período de anomia. O estado de anomia seria, então, um intervalo, um estágio de desregramento que antecederia uma nova acomodação social, em que as paixões estariam exaltadas e a competição pela busca da felicidade seria mais violenta, na medida em que as instâncias de mediação social estariam fragmentadas.

Não obstante, podemos afirmar que mesmo na contemporaneidade este estágio de desregramento se constitui como o modo efetivo do exercício do poder das sociedades de controle, o que pode ser evidenciado pelo apagamento das bordas entre a legalidade e a ilegalidade do ordenamento jurídico. Em Agamben (2002), o conceito de anomia é retomado acerca de sua análise sobre um novo estatuto dos espaços sociais da contemporaneidade, a saber, a partir da noção de campo. Ao se perguntar sobre a especificidade de um campo, o autor remonta sua argumentação acerca da primeira aparição destes espaços no cenário histórico, que talvez tenha se dado com os campos de concentração espanhóis, em Cuba em 1896, ou ainda, com os campos ingleses do início do século XX. De qualquer forma, em ambos os casos tratava-se da extensão a uma população civil inteira de um estado de exceção ligado a uma guerra colonial.

Toda esta démarche temporal é anterior ao episódio nazista, que se afirmou com a sofisticação deste exercício de poder, justificado, inicialmente, pelo argumento jurídico de uma polícia preventiva que, legitimamente, poderia tomar em custódia a vida de determinados indivíduos, com a finalidade única de resguardar o Estado de algum perigo suposto. Desta forma, a noção de campo diz de uma modulação contemporânea da ordem espacial do socius, capaz de emergir como positividade da supressão do ordenamento jurídico e de produzir, a partir da lógica da exceção, sujeitos legalmente inomináveis. 
Viveríamos, então, cotidianamente, na lógica de um estado de exceção possibilitado por uma zona de anomia social, produtora de grandes áreas-bolsões populacionais, os campos, que funcionariam segundo a lógica da exceção. Como bem sabemos, uma exceção é algo que está incluído num sistema de regras, mas se constitui como algo que está fora desta regra. Ou seja, há aqui certo paroxismo, pois o espaço do campo - como já apontamos - é o que emerge nesta área de exceção e é o que irá fazer a intersecção entre o dentro e o fora do ordenamento, estando simultaneamente inscrito nas duas lógicas, a da legalidade e a da ilegalidade. Nas palavras de Agamben (2002), experimentamos na contemporaneidade esta nova espacialidade nas periferias e favelas de algumas grandes cidades. Desta forma, vemos como as modulações na ideia de campo se fazem de acordo com uma nova especificidade do capitalismo global das sociedades contemporâneas, a saber, na busca desenfreada por manter num espaço de visibilidade/invisibilidade seguro aquilo que ameaça e se efetiva como efeito do próprio sistema, ou seja, amontoar em guetos e favelas todos aqueles que se constituírem como o refugo vivo do nosso tempo.

\section{A EXPERIÊNCIA BRASILEIRA}

No Brasil, podemos mesmo afirmar que desde a invasão portuguesa convivemos com toda espécie de práticas da violência. Essas violências se fizeram presentes numa política que dizimou toda uma população indígena, que escravizou milhares vindos do tráfico de escravos negros, que torturou e matou durante os anos da ditadura militar e que hoje ainda mata outros mais. Sabemos, ainda, que toda sociedade guarda sua especificidade histórica, mas não podemos deixar de admitir que, nos dias de hoje, todo caráter particular se encontra atravessado por um funcionamento mundial que não deixa de fora território algum. O capitalismo global contemporâneo, em seu movimento de incorporar novos mercados e produzir novas demandas, transforma e constrói o imaginário social, modula os discursos, desenha os contornos de uma subjetividade massificada e transforma toda singularidade em mercadoria exótica para ser consumida. Assim, somos levados a traçar um novo caráter assumido pelo fenômeno da violência na sociedade brasileira, a partir de sua articulação à nova especificidade do fenômeno da violência nas sociedades de controle global.

Malaguti (2003) traçou as linhas de convergência que ligam a crueldade histórica do processo de constituição do Brasil e as novas modulações que algumas dessas marcas irão assumir ao longo de nosso processo de modernização. Em seu livro $O$ Medo na cidade do Rio de Janeiro: dois tempos de uma história, ela mostra o conturbado processo de recrutamento de um enorme contingente de escravos africanos no período do crescimento da economia cafeeira e o aumento de uma população escrava que crescia, enquanto as atividades comerciais e industriais ganhavam importância econômica, ou seja, a riqueza começava a circular, o que foi determinante para a criação, em 1833, do primeiro aparato policial do Rio de Janeiro. Assim, institucionalizou-se um sistema de vigilância dos comportamentos, que tinha como função controlar os escravos, os negros livres, os mendigos, os pobres, para que as ruas da cidade ficassem livres para a "boa sociedade" - aristocratas, comerciantes e industriais - de modo que, quanto maior a preocupação com a propriedade privada, maior a vigilância dos espaços e maior o medo que começava a se instaurar naqueles reconhecidos pela sociedade: medo de que os escravos se rebelassem e se insurgissem contra aqueles que detinham os bens de produção; medo deste outro social, deste estranho, que ameaçava a paz imaginária de um bom funcionamento social. Assim tiveram início, no Brasil, todas as políticas de controle social que bem figuram até os dias atuais. Ancoradas na disseminação do medo, garantem-se e justificam-se antigas e novas práticas de extermínio, de encarceramento fechado e de controle aberto dos corpos que ameacem a boa vida de alguns poucos escolhidos para integrar a elite social.

Nada soa incoerente com nossos propósitos neste artigo. Foucault, como já descrevemos, analisou de forma brilhante as engrenagens do poder de disciplinamento e controle, tanto dos corpos individuais quanto das populações, do século XIX. No Brasil, o braço mais forte da disciplina parece ter sempre sido o braço da biopolítica das espécies, encarregado de cuidar da duração e da permanência de determinada população, mesmo que para esse fim precisasse empreender uma caçada mortífera a todos aqueles que fossem tomados como inimigos da sociedade. Se seguirmos com Malaguti (2003), no Brasil o escravo negro sempre foi equiparado a uma espécie de moléstia contagiosa, devendo ser isolado das famílias burguesas a fim de conter o avanço da contaminação por sua pestilência. Desse momento em diante começam a ser traçados no Brasil os contornos de um saber médico e criminal que deveria cuidar do esquadrinhamento dessa população, do controle e da propagação de suas doenças e da vigilância de sua circulação nas ruas da cidade. 
Se dermos um salto em direção ao século $\mathrm{XX}$, poderemos precisar a mudança de especificidade que $\mathrm{O}$ inimigo social ganhará ao longo do tempo. Quem será criminalizado e punido ao longo deste período? Machado da Silva, (1999) apontou que essa mudança de contornos ficará mais precisa a partir da década de 1970. Segundo o autor, até o final da década de 60 a criminalidade se estabelecia segundo uma lógica de organização, até certo ponto, paternalista e com hierarquias baseadas em laços de cumplicidade e lealdade. No Brasil, Machado da Silva se refere especificamente à organização das agências de jogo do bicho, que utilizavam a violência apenas como um recurso secundário em suas ações. Já a partir da década de 1970 a criminalidade começa a se "desestruturar" com as redes do narcotráfico. De acordo com Misse (1999), num primeiro momento, a organização das redes de narcotráfico se assemelhava em diversos aspectos à estrutura do comércio do jogo do bicho: em sua divisão de áreas, sua hierarquia entre os gerentes e vendedores, seus olheiros e pistoleiros, seu poder local e seu interesse político com a "proteção" dos moradores sob o seu raio de influência. No entanto, este tipo de composição foi sendo rapidamente redefinido.

Aqui é interessante fazermos uma dupla associação, representada pela passagem da criminalidade organizada em torno das organizações do jogo do bicho - cuja estrutura de poder se estabelece em termos de uma hierarquia quase que instransponível, já que herdada - e pela emergência do crime organizado em sua busca frenética pelo lucro imediato em sua fragmentação de poder em redes horizontalizadas, onde a conexão entre os componentes se faz e desfaz na medida do interesse e do acaso. Destarte o crime organizado passa a seguir a mesma lógica empresarial de mercado, e desta forma poderíamos tomá-lo, em suas inúmeras facções e grupos de controle do tráfico de drogas, a partir da análise da lógica empresarial produzida pelo capitalismo mundial integrado.

Essa passagem, porém, ainda não se deu numa contingência dos caminhos da história. $O$ contexto que viabilizou esta transição no modo operatório da criminalidade se efetivou a partir da abertura política que se iniciava na década de 80 . $\mathrm{O}$ fim da ditadura não pôs fim ao regime autoritário, o que interferiu diretamente no processo de abertura política de algumas instituições, principalmente as responsáveis pela ordem pública. Peralva (2001) nos traz como exemplo o caso da polícia militar, que em 1977 ganhou a proteção de uma "justiça corporativa", tendo em vista que somente os tribunais militares poderiam julgar seus oficiais.

Este resquício do regime autoritário interferiu diretamente nas políticas de segurança implementadas nos anos que o precederam. O modelo teórico para as políticas de segurança atuais é o resultado da sujeição à lógica militar de guerra assumida pela polícia. De acordo com Cerqueira (1996), não é possível entendermos como se deu esta interferência sem remontarmos, primeiramente, $\mathrm{o}$ processo de militarização da segurança influenciada teoricamente pela Doutrina de Segurança Nacional (DSN). Será, pois, neste momento que a ideia de segurança pública se confundirá com a noção de segurança interna. Segundo Coimbra,

(...) o ponto de partida da Doutrina de Segurança Nacional foi a revisão do conceito de defesa nacional. Concebido tradicionalmente como proteção de fronteiras contra eventuais ataques externos, este conceito, ao final dos anos 1950, mudou para uma nova doutrina: a luta contra o inimigo principal, "as forças internas de agitação". (Coimbra, 2002. p.31)

Ao fim do período militar a ideia de segurança nacional, já identificada à noção de proteção da sociedade contra seus inimigos internos, sofre um segundo deslocamento: muda-se a concepção desse inimigo. $\mathrm{O}$ alvo desta nova política de segurança não poderá mais ser aquele estudante, intelectual político que se insurgia contra o regime. A partir dos anos $80 \mathrm{o}$ inimigo interno será outro segmento da população, alienado de todos os benefícios obtidos com a abertura econômica do país. De acordo com Kolker (2002. p.42), "adaptada às exigências do projeto neoliberal, nossa política de segurança se volta especialmente para o controle, encarceramento e até extermínio das camadas mais pauperizadas do país, vistas como perigosas". É este o deslocamento na concepção da noção de inimigo a que nos referíamos anteriormente. $\mathrm{O}$ inimigo da contemporaneidade se constitui como um integrante ativo na movimentação em rede do capital e é circunscrito numa enorme massa populacional, que se integra ao sistema de gestão mas não poderá ser incluída na partilha dos lucros deste modelo.

O inimigo da contemporaneidade será a massa pauperizada (Wacquant, 2001), contabilizada como uma espécie de custo social à implementação do modelo neoliberal de gestão que, ao contrário dos espaços de confinamento disciplinares, deverão habitar o espaço do socius que lhes é destinado no 
biopoder, a saber, os campos, visíveis muitas vezes em periferias e favelas das grandes cidades.

Mais uma vez, o campo, ao contrário de um espaço de reclusão, situa-se no espaço absoluto de exceção ao ordenamento jurídico-político. Os campos representam o triunfo do biopoder em sua tarefa de incorporar nos mecanismos políticos e econômicos de controle do socius a vida nua, os fenômenos naturais concernentes à vida natural. Será em nome da preservação da vida, como já vimos em Foucault, que se lançará mão de estratagemas genocidas de destruição do outro, então concebido como ameaça à manutenção de uma determinada população. Neste ponto, o fundamental é a emergência de um novo estatuto social, no qual em alguns casos a vida perde seu valor jurídico e poderá, como consequiência, extinguir-se sem que seu extermínio configure um ato passível de condenação.

Talvez sejam os ecos deste controle genocida que se abatem sobre aqueles decretados como os inimigos da sociedade, que ouvimos no instante em que deixamos falar não só os ditos especialistas dos saberes, nem somente os responsáveis diretos pelas estratégias de controle violento, mas a própria população.

O que observamos hoje nas sociedades de controle é um aplainamento da verticalidade do exercício do poder em direção a uma horizontalização na forma de uma grande rede sem centro de emanação de poder. Não podemos mais pensar em uma fonte de emanação do poder que seja distinta do seu ponto de incidência, ou seja, numa relação de transcendência do exercício do poder. O que irá se estabelecer, na contemporaneidade, é uma estranha relação de imanência, onde há uma inseparabilidade entre a fonte do exercício do poder e o outro assujeitado por ele. Desta forma, tanto as relações entre os indivíduos quanto as relações dos agentes do Estado com a sociedade fazem parte desta mesma trama social violenta, e produzem discursos que apoiam práticas de extermínio em massa daquelas vidas consideradas "indignas de serem vividas". 4

4 A noção de "vida indigna de ser vivida", é retirada de um livro publicado em 1920, escrito por Karl Bending - um especialista do direito penal - e por Alfred Hoche, - um professor de medicina - intitulado A Autorização do Aniquilamento da Vida Indigna de ser Vivida. Nele, Binding e Hoche defendem a autorização da morte daqueles indivíduos considerados "incuráveis", seja por causa de uma doença adquirida desde o nascimento, ou ainda, por algum mal progressivo. Para eles, nesses casos, não haveria razão alguma, "nem jurídica, nem social, nem religiosa para não autorizar a morte desses homens, que não são mais do que a espantosa imagem do avesso (Gegenbild) da autêntica

\section{DESAFIOS À SUBJETIVAÇÃO}

Como já dissemos, este modelo que irá garantir sua eficácia numa sofisticada rede do biopoder não será sem consequências para os modos de subjetivação do contemporâneo, o que irá impor enormes desafios às tentativas de existências singulares. Afirmamos, desta forma, que não se trata de um sujeito anistórico, apartado das questões de seu tempo. $\mathrm{O}$ grande projeto alçado por Freud foi o de inserir as questões do sujeito na problemática de seu tempo. Assim, ao tratarmos das questões do sujeito, estamos da mesma forma imersos na problemática política de cada tempo, sustentando mais uma vez que sujeito e sociedade estão sempre em intrínseca relação.

É este o caminho de Sennett (1999) em seu livro A Corrosão do Caráter, onde se dedica especificamente à questão das novas relações intersubjetivas que se estabelecem a partir da atual estruturação do mundo do trabalho. De acordo com o autor, o capitalismo contemporâneo irá inaugurar uma nova dimensão temporal: será considerada contraproducente qualquer relação de longo prazo. Todos aqueles vínculos duráveis e estáveis, antes características apreciadas nas relações de emprego e entre pessoas, perderão força e serão suprimidos por relações cada vez mais velozes e fugazes. Vínculos como confiança e lealdade serão corrompidos numa sociedade que irá privilegiar, cada vez mais, a flexibilidade das relações, o desprendimento das tradições e a disponibilidade a correr riscos. Essa gradativa perda do estatuto fundamental, que até então regia as relações interpessoais baseadas no reconhecimento da alteridade, começa a perder toda a sua aspereza. Vemos, desta forma, a estruturação do vínculo intersubjetivo se confundir com o exercício violento de emancipação do capital.

A respeito deste aspecto da lógica contemporânea das sociedades de controle, Hardt e Negri, (2001), no livro Império, afirmam que, para se sustentar, a economia capitalista neoliberal depende da constante ampliação e conquista de novos territórios, ou seja, da incorporação e da criação de infinitos modos de existência, destruindo, para concretizar sua expansão, toda espécie de barreira social fixa. É o colapso das fronteiras fixas entre os territórios geográficos, das identidades enrijecidas, das instituições e seus regulamentos, e também das funções sociais, antes tão bem delimitadas.

humanidade". (Agamben, citado em Binding e Hoche, 1920: 145) 
Esta incansável produção de novos territórios existenciais fomenta uma espécie de trânsito frenético através das inúmeras possibilidades de afirmação subjetiva. O que se estabelece aqui é a reprodução da desregulamentação e da ruptura das antigas barreiras impostas pela lógica disciplinar, fundamental à expansão do capital, ao nível micropolítico das relações cotidianas; ou seja, as relações de constituição do socius adquirem, nas sociedades de controle neoliberal, a mesma violência disruptiva do movimento do capital.

De acordo com Guattari (1987), o modo de produção capitalista contemporâneo opera específicas formas de sociabilidade mediante um duplo mecanismo que desestabiliza signos sociais locais de reconhecimento para reestruturá-los numa formação global hegemônica de poder. Em sua análise do capitalismo, ele afirma que, após colonizar todos os espaços geográficos possíveis, o capital é forçado a se recompor internamente para continuar produzindo diferentes espaços para se apoderar e continuar a se expandir. Quando se esgota a possibilidade de expansão territorial para conquista de novos mercados, o capitalismo deverá, necessariamente, buscar crescer no próprio lugar. Assim, o movimento constante do capital deverá reinventar ao infinito os mesmos espaços.

Sendo assim, não faz sentido pensarmos numa categorização estanque em torno de determinados personagens contemporâneos, como é o caso do tão falado traficante do morro, ou ainda mais, numa sociedade cujas normas sociais mediadoras das relações entre indivíduos sejam totalmente degradadas, sem levarmos em conta a função utilitarista engendrada pelo Capitalismo Mundial Integrado. Este deverá se reconfigurar e criar, num processo contínuo e ininterrupto, inúmeras figuras sociais, assim como diferentes especificidades para cada novo personagem. Ainda que a ideia de inimigo social esteja, na contemporaneidade, necessariamente atrelada a um corpo, - podendo este ser tanto o do traficante de drogas como do terrorista, etc. - este se apresentará cada vez mais disforme, na medida em que deverá se modular de acordo as necessidades do capital. O inimigo deixará de ser um agente externo, que destoa de todo o conjunto de uma população e deverá ser eliminado para não ferir a ordem desejada, para se constituir, já em meados do século XX, como um produto próprio ao sistema capitalista mundial global.

Assim, a concepção de inimigo social ganhará um estatuto modulável em detrimento de seu antigo estatuto de contornos fixos. É como se assistíssemos a uma estranha corporificação de uma ideia, a de inimigo que prescindisse de uma forma específica. Sua forma se modularia na mesma medida da necessidade do capital em criar novos territórios existenciais com o intuito de perpetuar seu processo de expansão. No entanto, tomarmos a corporificação do estatuto do inimigo em personagens específicos e localizáveis como uma produção utilitarista e estratégica no processo de expansão do capital não significa assumir uma postura ingênua diante da realidade.

Não podemos, de um lado, cair no engodo produzido pelas análises mais simplistas, baseadas na ideia de uma afirmação identitária de um inimigo social que por sua natureza maligna deveria ser eliminado, encarcerado, reprimido, ou seja, colocado à parte do cotidiano do socius. Tampouco podemos desconsiderar que, por mais contingente que seja o novo estatuto assumido por esses inimigos sociais, eles não deixam de povoar nosso dia-a-dia. De acordo com Malaguti (2002), concentrar o medo numa parte da população que pode ser nomeada e localizada é absolutamente estratégico, pois privatiza o campo das inseguranças globais.

Para cada rosto moldado pelas políticas identificatórias a serviço do sistema capitalista contemporâneo há um papel a desempenhar: o de consumidore ou o de consumido. A política do medo irá traçar a linha de separação entre ambos. Estranha identificação que produz efeito de anonimato. Os "inimigos", aqueles estranhos que pelo medo serão banidos em guetos e favelas, ao serem nomeados ganham um lugar de resto social, sendo passíveis de serem consumidos, descartados, exterminados. De acordo com Debieux, Vicentin \& Catroli,

O empuxo à destruição do outro não é motivado pelas propriedades do objeto odiado, mas aponta um real que transcende aquele para o qual se dirige a agressão. $\mathrm{O}$ que se quer eliminar não é só aquele que está ali, mas o real, aquilo de insuportável e ingovernável que vem do real como o impossível de ser abarcado, representável, dominado..."(Debieux, Vicentin \& Catroli. texto inédito)

Mas, como dissemos, não apenas da modulação de identidades a serem exterminadas vive o Capitalismo Mundial Integrado. Todos aqueles que não forem convocados a compor este quadro específico do imaginário social contemporâneo desempenharão, de toda forma, outros papéis. Personagens na mais pura contingência do mercado, os consumidores irão assumir qualquer forma de 
objeto-mercadoria a ser substituído velozmente. Sujeitos ou corpos nus habitados por subjetividades fast-food?

Nisto reside uma das maiores dificuldades de todos os que se propõem a construir estratégias eficazes, sejam políticas públicas éticas e responsáveis de combate aos efeitos da violência do contemporâneo, sejam ferramentas clínicas que deem conta dos novos modos de subjetivação agenciados num espaço público onde a experiência da alteridade se faz sem rosto, os laços se fazem e se desfazem ao acaso do consumo e a singularidade da existência perde consistência e se apaga num anonimato engendrado por um horizonte desértico da mais completa dessubjetivação.

\section{REFERÊNCIAS}

Agamben, G. (2002) Homo Sacer: o poder soberano e a vida nua I. Belo Horizonte: Ed. UFMG.

Agamben, G. (2004) O Estado de Exceção. São Paulo: Ed. Boitempo.

Catroli, V. S. (2003) A lógica do controle global e sua estranha imanência: o caso do Brasil e a emergência de uma norma violenta de sociabilidade. Dissertação de Mestrado, Departamento de Psicologia, Universidade Federal Fluminense UFF, Niterói, RJ.

Cerqueira, (1996) Cerqueira, C. M. N. Remilitarização da segurança pública: a operação Rio. Em Discursos Sediciosos, $n^{o} 1$. Rio de Janeiro: Ed. Revan.

Coimbra, C. (2002) Doutrina de Segurança Nacional e produção de subjetividade Em Clínica e Política. Subjetividade e violação dos direitos humanos. Rio de janeiro: Ed. Te Corá e Instituto Franco Basaglia.

Debieux, M., Vicentin, C. \& Catroli, V. S. (2009) Viver em tempos sombrios: a experiência e os laços com os contemporâneos - texto inédito.

Deleuze, G. (1992) Post-scriptum sobre as sociedades de controle. Em Conversações. São Paulo: Ed. 34.

Durkheim, E. (1977) O Suicídio. Lisboa: Ed. Presença. (Original publicado em 1897).

Foucault, M. (1984) História da Sexualidade I: a vontade de saber. Rio de Janeiro: Edições Graal.
Foucault, M. (1987) Vigiar e Punir: história da violência nas prisões. Petrópolis: Ed. Vozes.

Foucault, M. (1999) Em Defesa da Sociedade. São Paulo: Ed. Martins Fontes.

Foucault, M. (2001) Os Anormais. São Paulo: Ed. Martins Fontes.

Guattari, F. (1987) Revolução Molecular: Pulsações Políticas do Desejo. São Paulo: Ed. Brasiliense.

Hardt, M. e Negri, A. (2001) Império. Rio de Janeiro: Ed. Record.

Kolker, T. (2002) "Tortura nas prisões e produção de subjetividade" Em Clínica e Política. Subjetividade e Violação dos Direitos Humanos. Rio de Janeiro: IFB e Te Corá Editora.

Machado, S. L. A. (1999) Criminalidade Violenta: por uma nova perspectiva de análise. Em Revista de Sociologia e Política, $n^{\circ} 13$ : cidadania e violência. p.115-124, Curitiba, UFPr.

Malaguti, V. (2002) O Globo da Morte. Em Clínica e Política. Subjetividade e Violação dos Direitos Humanos. Rio de Janeiro: IFB e Te Corá Editora, 2002.

Malaguti, V. (2003) O Medo na Cidade do Rio de Janeiro: Dois Tempos de uma História. (Tese de doutoramento). Instituto de Medicina Social, UERJ. 2003

Misse, M. (1999) Malandros, marginais e Vagabundos \& a Acumulação Social da Violência no Rio de Janeiro. IUPERJ. 1999. (Tese de doutorado em Sociologia).

Peralva, A. (2001) Violência e Democracia: o paradoxo brasileiro. São Paulo: Ed. Paz e Terra.

Quinet, A. (2003) O gozo, a lei e as versões do pai. Em Groeninga, Pereira (orgs.), Direito de família e psicanálise. Rio de Janeiro: Ed. Imago.

Sennett, R. (1999) A Corrosão do Caráter. São Paulo: Editora Record.

Vilhena, J. \& Santos, A. (2000) Quem cala consente. A cultura da violência e a ética da psicanálise. In: Psyche. Revista de Estudos Psicanalíticos. Vol. IV, n.5 São Paulo, Unimarco. pp:157-182.

Wacquant, L. (2001) Punir os pobres. Rio de Janeiro: Ed. Revan.

Recebido em 27/05/2008 Aceito em 04/02/2009

Endereço para correspondência : ～Viviani Sousa Catroli. 32, Rue Sainte-Marthe, 75010, Paris, França. E-mail: vivianisc@gmail.com 